\title{
Jihad: Duas interpretações contemporâneas de um conceito polissêmicol
}

Youssef Cherem MUDANÇAS NA DEFINIÇÃO DE JIHAD

(UNICAMP) Atualmente, principalmente depois dos atentados de 11 de setembro de 2001, a palavra "jihad" entrou no vocabulário corrente. A raiz j-h-d, da qual se origina, tem o significado geral de "esforço" ou "luta" (em inglês, geralmente traduzido como to strive, exert oneself, struggle). A palavra, em si só, nem sempre tem conotação religiosa ${ }^{2}$.

Com significado religioso, o jihad pode incluir uma luta contra as tentações ("jihad do coração", "jihad da alma"). Pode significar também o proselitismo do islã (da'wa) ou a defesa da moralidade ("comandar o bem e proibir o mal", al-'amr bilma'ruf wal-nahy 'an al-munkar) A noção de jihad desenvolvida pelos juristas islâmicos é de "guerra com significado espiritual" - jihad fi sabili "llah (jihad no caminho de Deus), jihad al-sayf (jihad da espada), sendo sinônimo, no Alcorão de qital fi sabili "llah ("luta", do verbo qatala, "matar"). A palavra árabe para "guerra", harb, geralmente é usada em contextos políticos.

A doutrina do jihad só se desenvolveu com o tempo (a partir do século II/ VIII). O termo jihad, embora com raízes profundas, é uma construção, em primeiro lugar, jurídica. Não há evidências, por exemplo, de guerras religiosas na Arábia préislâmica. ${ }^{3}$ Como lembra David Cook, o profeta Maomé nunca declarou um jihad (pelo menos não com esse termo), embora suas campanhas possam ser consideradas jihads prototípicos. Da mesma forma, as conquistas islâmicas dos séculos VII e VIII só foram classificadas como jihad depois, e não sabemos como os muçulmanos da época as chamavam (Cook 2005: 2). As narrativas da vida do Profeta (Sira) que contêm uma parte dedicada às suas expedições (maghazi). Os livros dos historiadores árabes medievais sobre a expansão do islã chamavam-se "Livro das Conquistas" (Kitab al-Futuh). As conquistas do império otomano na Europa não eram chamadas, pelos turcos, de jihad. Isso dissipa, por outro lado, afirmações de que o jihad é uma 
A historiadora Patricia Crone, em God's Rule: Six Centuries of Muslim Political Thought (2005), argumenta que o sentido original de jihad, nos primeiros séculos da era islâmica, era efetivamente o "imperialismo sob o comando de Deus", e que esse sentido só mudou no século IX, quando as fronteiras do mundo islâmico já estavam relativamente estabelecidas ${ }^{4}$. Nesse período, as conquistas das regiões centrais do império islâmico já estavam consolidadas.

A consolidação das conquistas através do domínio político foi instrumental para transformar a religião islâmica em majoritária. Só assim poderemos enquadrar melhor a polêmica em que se acusa o islamismo de ter-se propagado pela espada, ao que os muçulmanos respondem, citando o Alcorão, que "não há coerção na religião", e que as conquistas islâmicas foram "defensivas", no sentido de dar liberdade de propagação do islã. Na verdade, ambas as afirmações se complementam, e não poderia ser de outra forma com impérios ou reinos que não permitiriam a pregação do islã.

Foi só com o tempo - e o aumento das conversões de não-árabes para o islamismo - que a política islâmica conseguiu desagregar-se parcialmente de sua matriz árabe. A passagem da dinastia Omíada (661-750), caracteristicamente árabe, para a dinastia abássida (750-1258) representa uma mudança, com a conversão de uma parcela significativa da população (o islã vai progressivamente se tornando a religião majoritária) e a ascensão significativa de convertidos de outras etnias - notadamente persas e turcos - aos altos escalóes do poder e à elite intelectual e política. É nesse momento que se definem e cristalizam as doutrinas religiosas do islã, e foi também nesse tempo que a doutrina do jihad se desenvolveu, tal como a conhecemos hoje, por meio das escolas jurídicas islâmicas 5 .

É também a partir do século IX que, paralelamente ao desenvolvimento do jihad como jus belli pelos juristas religiosos, surge uma interpretação do jihad como luta espiritual. Essa distinção está fundamentada na tradição frequentemente citada: "Alguns combatentes vieram até mensageiro de Deus e ele disse: Fizestes bem em vir da 'pequeno jihad' (al-jihad al-asghar) até a 'grande jihad' (al-jihad al-akbar)". Eles disseram: O que é a grande jihad?. Ele respondeu: É o servo [de Deus] lutar contra suas paixões" (citado em Cook 2005: 35) ${ }^{6}$.

O jihad permanece com um significado ambíguo desde então - um jihad dos juristas (fuqahá, sing.: faqih) ou doutores da lei (ulemás), e outro dos místicos (sufis) ${ }^{7}$. Devemos notar que o sentido espiritual não nega o sentido material, sendo o "jihad da espada" (jihad al-sayf) muitas vezes um complemento ou uma extensão do "jihad da alma" (jihad al-nafs), e que a moral e a "boa intenção" — de lutar para a glória de Deus — estão subentendidos na caracterização do jihad.

O jihad é, em todos os seus sentidos, uma parte do testemunho (shahada) de Deus no mundo. Considerandose que, nos dois impérios aos quais se contrasta a islâmica nascente na Península Arábica — o Império Bizantino e o Império Sassânida da Pérsia - , a estrutura do poder estava profundamente imbricada com as instituições religiosas, a preservação e livre pregação da mensagem islâmica, bem como a própria sobrevivência da comunidade religiosa islâmica (umma) nascida em Medina, implicavam num esforço (literalmente: jihad) ao mesmo tempo político, militar e religioso. Assim, o objetivo primordial do jihad é simplesmente a conquista por si só, mas "elevar 
a palavra de Deus", como diz um hadith ${ }^{8}$.

A existência ou não de jihad, então, encontra-se na intenção individual. Jihad é uma concepção de guerra, não o fato em si de haver guerra, e nem mesmo se essa guerra for feita "em nome de Deus", mas sem incluir o objetivo primordial que é engrandecer o nome de Deus. O jihad é um tipo de luta ou esforço, o empenho de um indivíduo para o seu próprio bem (jihad al-nafs) ou para o bem coletivo (a pregação ou, em última instância, a luta armada).

É necessário salientar que esse "engrandecimento" não é obrigatoriamente a vitória na guerra. Das duas coisas, uma: ou o guerreiro morre e recebe uma recompensa no paraíso, ou ele vence e ganha o botim. Ou Deus vence no coletivo e material (vitória e conquista), ou vence no individual e espiritual (ascensão ao paraíso). A ascensão ao paraíso significa um contrabalanço do que se ganharia na vitória terrena: só há vitória, a morte não é significado de perda, mas sim, de ganho. Além disso, a morte de uns pode parecer necessária para a vitória da coletividade, e o que ele ganha no céu compensa o que ele ganharia na terra. É por isso que, nas descrições do paraíso, em imagens vívidas, suntuosas e exuberantes, os mártires têm um lugar especial.

Não se deve pensar, portanto, que o jihad sempre foi somente ascético, uma resignação em morrer para engrandecer a palavra de Deus aos olhos do mundo através da retribuição para Deus daquilo que Deus deu de mais precioso (a vida). Esse significado existe, especialmente na vida e na obra dos ulemás ${ }^{9}$ que combinavam, na fronteira com povos não-muçulmanos, o estudo, a guerra, e, às vezes, o misticismo. Mas essa vivência não é a preponderante, antes das grandes conquistas islâmicas dos séculos VII-VIII.

É durante os séculos XIX e XX que intelectuais islâmicos enfatizaram o sentido espiritual ou defensivo do jihad e tentando minimizar seu componente ofensivo, reinterpretando a história para responder à acusação de que o islã é uma religião que prega a violência e a intolerância. Nas literaturas das línguas tradicionais do islã (árabe, persa, turco, urdu, malaio/indonésio), o significado permanece ambíguo.

Sem querer tomar partido em uma disputa teológico-política (a supremacia de uma ou outra versão do jihad), pretendo neste artigo iluminar as escolhas interpretativas, as releituras e reapropriações da vertente da tradição islâmica que privilegia o chamado jihad al-sayf (o "jihad da espada") nos sentidos de luta armada, incluindo aí a guerrilha e terrorismo. Para tanto, apresentarei a leitura do conceito de jihad segundo dois pensadores e ativistas islamistas contemporâneos ligados à luta armada - Sayid Imam e Yusuf Uyayri ${ }^{10}$.

\section{MUTAÇÕES: JIHAD COMO GUERRILHA E JIHAD COMO TERRORISMO}

Com o advento da era dos estados-nação e do colonialismo, o jihad assumiu um caráter apologético e/ou missionário, mesclando-se com doutrinas políticas ocidentais e formas de ativismo social ou político (incluindo a guerra entre Estados, guerrilha e o terrorismo). Como forma de resistência, assimilou-se à guerra ou guerrilha contra a invasão estrangeira no Marrocos e na Argélia, no Cáucaso (Tchechênia e Daguestão), estando associado também a conquistas territoriais como a dinastia mogol na Índia (1526-1857), o Califado de Sokoto no século XIX na atual Nigéria, e o estado Mahdista no Sudão (1881-1898). 


\section{Jihad como terrorismo}

Carregado de conotações valorativas, tem-se evitado definir o termo "terrorismo" ou, em meios acadêmicos, até mesmo empregá-lo. $\mathrm{O}$ argumento corrente é que é impossível defini-lo sem entrar em juízos de valor. Segundo a tão usada expressão: “One man's terrorist is another man's freedom fighter". Mas, ainda assim, é necessário aventar uma definição operacional. Seguimos a definição de terrorismo do sociólogo Donald Black: “O terrorismo em sua forma pura é autoajuda por civis organizados que clandestinamente infligem violência em massa contra outros civis" (Black 2004:10) ${ }^{11}$. Os jihads do século XX, tendo objetivos nacionais (derrubar o governo e implantar um estado islâmico) ou internacionais (exportar a "revolução islâmica" e criar um império que una toda a umma), compartilham essas características.

\section{Jihad transnacional: terrorismo, "luta moral" e way of life}

Ao caracterizar o jihad moderno como guerra de libertação nacional, guerrilha ou terrorismo, devemos levar em conta tanto sua especificidade quanto as características que compartilha com outros movimentos semelhantes. Recentemente, o "modelo estratégico" do terrorismo tem sofrido várias críticas. Em resumo, este modelo afirma que grupos ou agentes terroristas atuam segundo a "lógica da conseqüência", quer dizer, age segundo a efetividade percebida de sua ação, escolhendo entre opções disponíveis a mais favorável a seu(s) objetivo(s). O modelo estratégico é fundado em três premissas: 1) os terroristas são motivados por preferências políticas relativamente estáveis e consistentes; 2) avaliam os payoffs esperados das opções disponíveis; 3) o terrorismo é adotado quando o seu retorno político é percebido como superior a outra estratégia (Abrahms 2008).

No entanto, o que se percebe na ação dos grupos terroristas é que sua própria estratégia (o terrorismo) contradiz seus objetivos. Max Abrahms cita sete "paradoxos" do terrorismo segundo uma perspectiva racionalista: 1) As organizações terroristas não atingem seus objetivos ao atacar civis; 2) nunca usam o terrorismo último recurso e raramente aproveitam oportunidades para se tornar partidos políticos não-violentos; 3) rejeitam compromissos e concessões significativas de seus alvos e são intransigentes em relação aos seus objetivos; 4) possuem uma plataforma política disforme; 5) geralmente realizam ataques anônimos, impossibilitando concessões dos governosalvo; 6 ) organizações terroristas com plataformas políticas idênticas costumam atacar mais a si mesmas do que seu inimigo declarado; 7) organizações terroristas resistem à sua dissolução, tanto quando fracassam quanto quando seus objetivos políticos são atendidos (Abrahms 2008: 82).

No levantamento feito por Abrahms em 2006, de 28 grupos terroristas com 42 objetivos políticos, a taxa de sucesso dos atentados foi de somente $7 \%{ }^{12}$. Mesmo assim, o sucesso só ocorreu quando os alvos foram militares, e seus objetivos, territoriais. Pelo contrário, ações visando civis nunca promoveram a causa dos grupos, e objetivos ideológicos (transformar o sistema político, aniquilar o inimigo por causa de seus valores) nunca foram atingidos 
(Abrahms, 2006). Abrahms (2006) explica esse resultado negativo pela percepção, no país-alvo, de que os resultados da ação correspondem às intenções dos seus realizadores. A conclusão das vítimas com base nos efeitos do terrorismo (mortes de inocentes, pânico, falta de confiança no Estado como provedor de segurança, perdas econômicas, ameaças ao Estado de direito) é que eles são evidências de uma vontade deliberada de destruição do seu sistema sócio-político.

O terrorismo se torna, então, contraproducente. A resposta dos Estados Unidos aos ataques de 11 de setembro de 2001 foi justamente o oposto do resultado esperado pela al-Qaida ${ }^{13}$ :

\begin{tabular}{|l|l|}
\hline \multicolumn{1}{|c|}{ Objetivos da al-Qaida } & \multicolumn{1}{|c|}{ Resposta dos Estados Unidos } \\
\hline Retirada das tropas americanas da Península Arábica. & $\begin{array}{l}\text { Aumento de } 15 \text { vezes no número de tropas americanas } \\
\text { no Golfo } \\
\text { Pérsico. }\end{array}$ \\
\hline $\begin{array}{l}\text { Dissuadir intervenções militares que matem } \\
\text { muçulmanos (no mundo todo). }\end{array}$ & $\begin{array}{l}\text { As operações contra o terrorismo mataram direta ou } \\
\text { indiretamente milhares de civis e inocentes no mundo } \\
\text { muçulmano. }\end{array}$ \\
\hline Fim do apoio a ditadores muçulmanos pró-ocidente. & $\begin{array}{l}\text { Fortalecimento das relações militares, especialmente } \\
\text { com Paquistão, Arábia Saudita e os regimes instalados } \\
\text { em Cabul e Bagdá. }\end{array}$ \\
\hline Resolução da questão palestina. & $\begin{array}{l}\text { Processo de paz parado e escalada da violência com } \\
\text { ascensão de Ariel Sharon ao governo de Israel. }\end{array}$ \\
\hline
\end{tabular}

Finalmente, à parte o 11 de setembro, os objetivos da al-Qaida são tão difusos, tão heterogêneos, desfocados e confusos, que no final das contas não nos espanta que não haja qualquer proposta objetiva para remediar a situação. A resposta, afinal, não é política - é moral. Os homens tornar-se-ão bons quando reinar a shari'a por toda parte, ou, em outras palavras, quando aceitarem a shari'a, por bem ou por mal. Uma pequena lista dos objetivos da al-Qaida ou das causas pelas quais eles lutam (baseado em Lawrence \& Howarth 2005 e Ibrahim 2007):

- causas territoriais: Palestina; Índia; Somália; Tchetchênia; Cachemira; Líbano; Molucas; Iraque;

- todos os governos de todos os países árabes e/ou muçulmanos, considerados infiéis e/ou seculares por não aplicarem a shari'a. 
Respondendo à questão: "o que vocês querem", Bin Laden enumera seus objetivos ou desejos em relação aos Estados Unidos. Na verdade, o que Bin Laden faz é uma longa lista dos "pecados" dos Estados Unidos:

- os Estados Unidos são o país da "opressão, mentiras, imoralidade, depravação, fornicação, homossexualidade, intoxicação, apostas e usura";

- estabeleceram a democracia e a Constituição no lugar da Lei de Deus;

- exploram as mulheres como mercadoria;

- fazem do sexo uma indústria;

- espalham doenças devido a seu comportamento promíscuo;

- destroem a natureza e poluem o meio-ambiente e mesmo assim não assinaram o Protocolo de Kyoto;

- lançaram as bombas atômicas de Hiroshima e Nagasaki;

- têm "dois pesos e duas medidas" e agem segundo seus interesses egoístas na política internacional;

- não respeitam o Direito Internacional;

- não respeitam os Direitos Humanos.

O primeiro desejo de Bin Laden para suprimir esses males e remediar a situação é que os americanos se convertam aos islamismo. Ele também quer que os EUA deixem de apoiar Israel, Índia, Rússia e Filipinas na luta contra os muçulmanos; que deixe de apoiar os governos "corruptos" dos países muçulmanos; que não interfiram na política desses países ou no seu método de educação; e que lidem com eles em pé de igualdade e não de uma posição de superioridade. Em suma, Bin Laden deseja que os EUA deixem de ser e agir como superpotência, e afirma que, se os EUA "não cumprirem todas essas condições", devem se preparar para lutar com a "Nação do Monoteísmo", à qual Deus prometeu a vitória (Lawrence e Howarth 2005). Ora, tais condições são inatingíveis, e um programa de ação política baseado nelas está fadada ao fracasso.

Mas se o jihad global "não funciona", se não alcançou nem vai alcançar nenhum de seus objetivos, por que sua ideologia ainda é tão atraente, seja no nível real, seja no mundo virtual da internet, onde proliferam os mujahidin virtuais? Para responder a essa pergunta, a jihad e o salafismo devem ser postos no contexto da modernização, racionalização e individualização da religião, bem como dos novos movimentos religiosos e novas formas de expressão social e política.

Os movimentos armados islâmicos, principalmente a partir da invasão russa no Afeganistão (década de 1980), têm-se baseado em grande parte na doutrina salafista. Vários intelectuais islâmicos no campo religioso muçulmano sunita internacional ou transnacional - e, especialmente, muitos "teóricos do jihad" - reivindicam o epíteto de "salafistas".

Por salafismo, aqui ${ }^{14}$, entendemos doutrina originada com o reformador religioso Muhammad lbn Abd alWahhab (1703-1792) da região de Najd (centro da Península Arábica). Seus seguidores são geralmente conhecidos para os que não aderem à sua doutrina como "wahhabitas", uma designação à qual se opõem, chamando a si 
mesmos de salafiyun, ou seja, seja, seguidores dos "pios ancestrais" (salaf al-sâlih). Os salaf eram compostos pelas três primeiras gerações de muçulmanos, que tiveram experiência direta do islã em seus tempos de glória e, portanto, são exemplos de conduta para os muçulmanos das gerações seguintes Os salafistas também se designam como muwahhidun (unitaristas ou monoteístas) ou ahl al-tawhid (povo da unicidade [de Deus]). Abd al-Wahhab e seus seguidores defendiam uma interpretação literal do Alcorão e das Tradições do Profeta (hadith), criticando as escolas jurídicas tradicionais. A doutrina de Abd al-Wahhab baseia-se na noção central de tawhid, unicidade de Deus. Segundo ele, várias práticas correntes entre os muçulmanos feriam o princípio fundamental do monoteísmo de que só Deus deve ser adorado. Assim, Abd al-Wahhab condenava o culto dos santos, o sufismo, práticas religiosas populares (astrologia, amuletos, adivinhação) e o xiismo como "politeísmo" (shirk, "associação" de outras entidades a Deus) ou "descrença" (kufr). Quem as praticava e não aderia à sua noção de tawhid era considerado infiel (kâfir) ou apóstata (murtadd); e, após essa declaração de infidelidade ou "excomunhão" (takfir), o jihad poderia ser declarado contra eles (Meijer 2010). Outro conceito fundamental da visão de mundo wahhabita é a noção de al-walá wal-bará, significando lealdade, solidariedade e dedicação (walá) a Deus, ao Islã e aos outros muçulmanos, e hostilidade, ódio, repúdio, desligamento e negação (bará) de todo o resto (Wagemakers 2008a; 2008b).

Abd al-Wahhab uniu-se à casa de Al-Saúd, que conquistou a Península Arábica entre os séculos XVIII e XIX, e criou o Reino da Arábia Saudita no século $X X^{15}$. Devido a essa aliança, uma das características mais marcantes do movimento salafista é sua postura não-política, de submissão e apoio à casa real saudita, com uma divisão de esferas de controle entre dois grupos sociais: a arena política à família dos Saúd, e a educação, espaço público e religião, os doutores religiosos (os ulemás). Segundo a visão wahhabita tradicional, só o soberano poderia declarar jihad. É essa visão que vai ser criticada durante o século $X X$, culminando em movimentos salafistas políticos (violentos ou não) ${ }^{16}$.

A corrente religiosa/política da qual a pertencem organizações como a al-Qaida - e à qual são ligados os dois autores aqui examinados - define-se como "salafista-jihadista" (em árabe, salafi-jihadi) ${ }^{17}$. Os salafistas-jihadistas caracterizam-se pela sua reinterpretação de conceitos centrais aos salafistas (tawhid, kufr, al-walá wal-bará), dandoIhes um sentido de revolução e luta armada, e não passividade ante a esfera política. Assim, o sentido de tawhid engloba também a não-submissão aos governantes ímpios, considerados como ídolos (taghut), o repúdio às leis seculares e à democracia, consideradas um abuso e uma usurpação do direito de Deus como único legislador, e uma linha de divisão estrita e separação dos infiéis e solidariedade entre os crentes (al-walá wal-bará), que leva, em última instância, à declaração de guerra (jihad).

Há várias perspectivas sobre a ideologia salafista e/ou jihadista, inseridas no panorama mais amplo do islamismo político ${ }^{18}$.

Uma primeira perspectiva vê o surgimento dos Estados modernos em países de maioria muçulmana como um processo resultado do encontro conflituoso com as potências europeias em expansão a partir do século XIX. O islamismo político teria sido, de alguma forma, uma resposta ou um dos resultados dos impérios ou sociedades islâmicas com as potências europeias, criando-se uma relação de repulsão-atração em face de escolhas, dilemas 
e ambiguidades que variam entre assimilação/resistência, diálogo/conflito, recusa/aceitação/adaptação etc. Seria, assim, uma resposta política baseada numa identidade cultural reivindicada como particular, como outros exemplos paralelos dos países que conquistaram sua independência durante o século XX na África e na Ásia. Mas, num primeiro momento, os movimentos nacionalistas não apelaram à religião sistematicamente como fator aglutinador e mobilizador na política anticolonialista. Podemos notar que em quase todos os países árabes a criação de um Estado moderno implicou na valorização de elementos linguísticos ou culturais, com a criação de repúblicas laicas ou monarquias em tese constitucionais, com predomínio até a década de 1960 da ideologia pan-arabista e republicana de Gamal Abd al-Nasser.

Assim, num ambiente predominantemente nacionalista, o surgimento dos Irmãos Muçulmanos, na década de 1920 no Egito pode ser interpretado como uma reação à ideologia nacionalista. Nessa linha, Gilles Kepel (2003a; 2003b) vê o projeto islamista como um projeto cultural, oposto principalmente ao nacionalismo. O modelo dos Irmãos Muçulmanos, de um grande partido de massas bem organizado e estruturado, expandiu-se, sendo criadas "filiais" em todo o mundo árabe. ${ }^{19} \mathrm{O}$ dilema enfrentado pela perseguição do regime Nasserista foi interpretado por Kepel (2003) como uma das principais razões da radicalização de militantes islâmicos em suas transformação em organizações como a Organização do Jihad (Tanzim al-Jihad), responsável pelo assassinato do presidente egípcio Anwar al-Sadat, que depois deu origem a dois grupos, o Jihad Islâmico (al-Jihad al-Is/âmi) e o Grupo Islâmico (alGamaa al-(s/amiya). Sayid Imam foi chefe do Jihad Islâmico por um tempo, sendo substituído por Ayman al-Zawahiri.

Segundo outra corrente, os movimentos islamistas não correspondem a um modelo ideológico político no sentido estrito. A política islamista, principalmente a dos movimentos militantes radicais, é, em grande parte, uma ética política, sendo difícil separá-los de outros movimentos devido a um programa, uma causa, ou objetivos políticos (Roy 2004; Devji 2005). Por isso esses movimentos se alinham ao mesmo tempo a causas nacionalistas, terceiro-mundistas e esquerdistas, além de um programa socialmente conservador baseado no domínio dos preceitos religiosos de comportamento na esfera pública. De fato, grande parte do apelo de movimentos islamistas como o Hamas ou os Irmãos Muçulmanos vem, além do aspecto mais visível de seu trabalho social (hospitais, escolas), pelo fato de serem considerados íntegros e coerentes na política.

Finalmente, outra perspectiva é a dos movimentos sociais (Wiktorowicz 2003). À primeira vista, ela não aplicaria ao movimento salafista e/ou jihadista, na maioria dos casos, a não ser que entendamos que são movimentos sociais que não podem ou não querem se inserir na sociedade civil (ver raras exceções em Wiktorowicz 2001 e Al-Rasheed 2006).

Neste artigo, analisaremos a obra de dois pensadores islamistas da perspectiva da ênfase que eles dão no engajamento pessoal e nas motivações morais para integrar o movimento islâmico global. A inovação de seu pensamento em relação à doutrina jurídica clássica do jihad, seja das escolas jurídicas tradicionais, seja da leitura wahhabita, reside não tanto na direito/ética de guerra (jus ad bellum), mas sim na fundamentação menos jurídica que fazem do jus ad bellum (as razões legítimas para uma guerra justa) ${ }^{20}$. 
Uma perspectiva do jihad como reciprocidade (uma promessa de Deus, um pacto com Deus) é-nos dada por Sayid Imam al-Sharif, também conhecido como Dr. Fadl. Fadl foi líder o grupo Jihad de 1987 a 1993, do qual depois se separou, criticando severamente a al-Qaida em seus escritos posteriores (Wright 2008).

Em 1988, sob o pseudônimo de 'Abd al-Qadr ibn 'Abd al-Aziz, Sayid Imam publica o livro Os pilares para a preparação para o jihad no caminho de Deus o Altíssimo (al-Umda fi l'dad al-'Udda lil Jihad fi Sabilillah al-Ta'ala) que se destinava a ser uma apostila para os recrutas dos campos de treinamento do jihad no Afeganistão. No capítulo intitulado "As cinco bases para conseguir a tradição da vitória ou sua ausência" (al-Usul al-Khamsa li Tahaqquq Sunnat al-Nasr aw Takhallufiha) (Abd al-Aziz 1988), Fadl desenvolve uma explicação para a vitória e a derrota no jihad. Para Fadl, a vitória é material: foi prometida para este mundo (dunya). É também uma graça de Deus - só existe vitória em Deus ou através dele (wa ma al-nasr illa min 'and allah, suras Imran 126 e Anfâl 10). Temos então uma explicação redundante (e, por isso mesmo, satisfatória) para a vitória e a derrota no jihad. Parte-se do postulado de que a fé, assim como a vitória, pode ser dividida. Assim, o nível de vitória é diretamente proporcional ao nível da fé: "A vitória é prometida somente àqueles de fé completa, e cada um será tanto mais vitorioso quanto maior for sua fé" (Abd al-Aziz 1988). Este mundo é visto como um lugar de provação aos pecadores, como sinal de advertência, para se regenerarem. $O$ insucesso é, então, evidência da falta de fé. A culpa pela derrota está sempre numa falha humana no nível da fé, quer dizer, uma falha não material. Fadl não cogita a possibilidade de uma vitória devido à superioridade material, ou de uma derrota de virtuosos na fé, mas incapazes na guerra. Parece que a preparação material é uma parte necessária do esforço moral e espiritual no jihad. No argumento de Fadl, não fica claro se o "nível de fé" do qual ele fala diz respeito ao nível da umma como um todo, ou se essa fé é "medida" (provada/ comprovada) em episódios separados ou num contínuo temporal. Uma conclusão incômoda mas necessária do seu raciocínio seria de que Maomé perdeu ou não venceu batalhas porque ele não tinha fé o bastante - o que é um absurdo para a doutrina "ortodoxa" muçulmana, que vê em Maomé o ápice da perfeição humana. Além disso, Fadl não lida com a questão de se a vitória ou a derrota são individuais ou coletivas, ou qual seria a proporção de virtuosos (muçulmanos) no meio de pecadores (muçulmanos) lutando juntos no jihad para que haja vitória.

\section{Yusuf al-Uyayri: vitória no jihad é o próprio cumprimento do dever}

Yusuf bin Salih bin Fahd al-Uyayri nasceu em 1974 em Dammam, Arábia Saudita. Deixou a escola aos 18 anos, para ir combater no Afeganistão, onde chegou em 1991. Al-Uyayri acompanhou Bin Laden no Sudão em 1992. Posteriormente, voltou à Arábia Saudita para levantar fundos para a luta na Bósnia e no Kosovo. Foi preso e acusado de envolvimento com o atentado contra a base americana de Khobar, na Arábia Saudita, em 1996, onde se alega que foi torturado. Solto em 1998, começou a escrever sobre a causa do jihad, dedicando-se primeiro à causa chechena e, após 2000, principalmente ao Afeganistão. Uyayri publicava no seu Instituto para Pesquisas e 
Estudos Islâmicos (Markaz al-Buhûth wal-Dirasât al-Islamiyya) e em vários sites sauditas. Uyayri acabou sendo mais conhecido como o líder da al-Qaida na Península Arábica, recrutando e treinando os líderes da organização. Uyayri morreu num confronto com a polícia em $2004^{21}$.

Os significados de vitória e derrota no jihad, segundo Yusuf al-Uyayri, são, antes de tudo, individuais, e os objetivos do jihad, particularistas. O jihad é um bem em si mesmo (um dever a ser cumprido porque Deus manda), uma forma de expiar pecados, alardear a verdade da religião islâmica (o martírio como confirmação direta da fé e evidência indireta, mas persuasiva, da verdade). Acima de tudo, é o caminho mais simples para se obter uma garantia da salvação, de se ter certeza que se vai ao paraíso e não ao inferno depois da morte. A vitória no campo de batalha é só um entre dez tipos de vitória, e não é o mais importante. Para Uyayri (al-Uyayri 2009 ; al-Uyayri s/d), os significados de "vitória" no jihad são:

- vitória sobre as coisas materiais (possessões, família) e sobre sua alma (força de vontade, autocontrole);

- vitória sobre o demônio que se coloca no caminho do jihad;

- porque Deus guiará o mujâhid, segundo o Alcorão (29:69): “Quanto àqueles que diligenciam por Nossa causa, encaminhá-los-emos pela Nossa senda. Sabei que Deus está com os benfeitores";

- vitória sobre os que desencorajam o jihad;

- resistência, firmeza e persistência;

- glória e honra: lutar pela religião já é uma vitória em si, independente do resultado material;

- Deus destruirá os inimigos dos mujahidin, assim como destruiu as nações dos profetas (Mujahidin, então, com status semelhante aos profetas);

- porque o jihad causa a perdição eterna dos infiéis, desviando-os ainda mais, até a morte;

- o martírio também é uma forma de vitória, pois o mártir entrará certamente no paraíso;

- vitória das ideias (mesmo se houver fracasso ou martírio);

- a vitória no campo de batalha, que é somente uma das formas de vitória.

Já para derrota temos poucas variações. Em suma, só pode haver derrota no caso de se abandonar a luta. E, se isso acontece, deixa-se, de alguma forma, de ser muçulmano. Especificamente, Uyayri entende como "derrota" no jihad:

- seguir a cultura dos infiéis (judeus, cristãos, secularistas, baathistas, comunistas, democratas, modernistas) ou seus desejos, no todo ou em parte;

- aceitar a supremacia dos infiéis;

- agir com brandura para com os infiéis;

- inclinar-se para os infiéis; 
- obedecer os infiéis;

- perder a esperança em Deus;

- deixar o jihad;

- abandonar a esperança numa vitória militar;

- temer o inimigo.

No seu livro Thawâbit 'ala Darb al-Jihad (Constantes no Caminho do Jihad), Uyayri desenvolve mais o tema dos benefícios do jihad. O jihad, em si, aumenta a fé. Não se deve entrar no combate racionalmente, isto é, medindo os resultados. $\mathrm{O}$ jihad tem um valor moral intrínseco de cumprimento do dever:

Devemos fazer algo não porque isso nos trará vitória ou por causa do resultado, mas devemos fazê-lo porque Deus no-lo ordena. Somos soldados de Deus; devemos esquecer os resultados e fazer o que Deus manda. Deixamos tudo nas mãos de Deus. Nós não conhecemos o que é oculto (al-Uyayri s/d).

O sucesso no combate é, então, para Uyayri, uma graça de Deus, não uma promessa de Deus de uma recompensa para os méritos da fé, como para Dr. Fadl. Para Uyayri, o sucesso não é resultado da fé: é inescrutável, incerto, duvidoso e incomensurável; já para Dr. Fadl, o sucesso material é certo e líquido. Uyayri aceita que pode haver derrota devido aos pecados, mas, para ele, a derrota no campo de batalha também tem outras duas causas: Deus pode querer testar seus servos, ou pode querer purificá-lo (al-Uyayri s/d).

Para Uyayri, fazemos o que Deus manda, e, se o resultado é bom ou ruim, cabe a Deus decidir. Segundo ele, se pensarmos somente nos resultados, "estaremos tratando o nosso islã como um negócio, julgando o sucesso de acordo com os resultados". Mas, se houve batalhas que o profeta perdeu (como Uhud), não podemos julgar uma ação pelo seu resultado. A ética que importa, para usar uma terminologia weberiana, é a ética da convicção, e não da responsabilidade. Em termos kantianos, o jihad seria algo como um "imperativo categórico": um requerimento necessário, absoluto e incondicional, justificado como um fim em si mesmo, independente dos resultados (Kant, 1993 [1785]). Assim, "nunca julgue os meios baseado nos fins", diz Uyayri (al-Uyayri s/d). Uma das consequências nefastas de julgar segundo padrões materiais de sucesso, segundo Uyayri, é que isso leva à infidelidade (kufr) e ao desespero.

\section{CONCLUSÃO}

De uma ideologia imperialista árabe de conquista nos primeiros séculos do islã, o conceito de jihad passa a um momento mais universalista de consolidação, expansão e defesa da fé e de sua comunidade, agregando, por fim, conceitos políticos advindos do contato com o ocidente: jihad como luta anticolonial e/ou nacionalista e, finalmente, como guerrilha, terrorismo, luta moral, modo de vida e disciplina espiritual. A especificidade das leituras do jihad em contextos contemporâneos é que ele se individualiza, tornando-se, ele próprio, um "modo de vida" e uma 
escolha no plano individual, ao mesmo tempo em que é uma missão, uma ideologia, e uma doutrina religiosa, no plano coletivo, como evidenciado nas obras de Sayid Imam e Yusuf al-Uyayri, em que é clara a concepção do jihad como luta moral e ascese.

Youssef Cherem é professor do Departamento de História da Arte (UNIFESP) Guarulhos), bacharel em Relações Internacionais (PUC-MG), mestre e doutor em Antropologia Social pela UNICAMP. 
1 Este artigo é uma versão modificada de um capítulo de minha tese de doutorado em Antropologia Social pela UNICAMP: A crença, a lei e a guerra: uma análise do pensamento de Isam Muhammad Tahir al-Barqawi, defendida em 2010.

2 Tanto que pode ser até nome próprio masculino, inclusive cristão, no Oriente Médio.

3 As expedições, incursões ou razzia (ghazwa, pl. ghazawat) eram uma característica da sociedade tribal árabe pré-islâmica. Eram praticadas contra grupos que não tinham relação de parentesco ou clientela, e era um meio importante de adquirir ou redistribuir recursos numa economia de excedentes escassos. Os grupos nômades procuravam butim ou extorquiam tribos mais fracas. Devido ao medo de vingança, evitava-se tanto quanto possível o derramamento de sangue.

4 A característica principal do jihad nas primeiras conquistas é que a universalidade da mensagem islâmica é uma universalidade política, mas não religiosa. Isso se torna evidente pelo fato de que, com raras exceções, não ocorreram conversões forçadas. Mas as conversões que aconteciam implicavam na submissão política e na inserção na sociedade árabe, tornando-se cliente. A opção de conversão ao islã era uma característica nova em relação à idéia de "guerra sob comando de (um) Deus" na antiguidade do Oriente Médio, mas a concepção de religião ainda era particularista: "A religião estava sendo usada para validar o domínio de um único povo, ou engrossar suas fileiras, e não para unir a humanidade numa única verdade acima de divisões étnicas e políticas [...]. O jihad, como era entendido pelo grosso dos árabes tribais, era imperialismo árabe sob comando de Deus" (Crone 2005: 367). Isso tornava especialmente incômoda a existência de árabes não-muçulmanos. Como a mensagem de Deus foi revelada em árabe, não havia razão para que um árabe (ou uma tribo árabe) não a aceitasse. Embora a sua situação não tenha sido tão crítica como a dos árabes politeístas, que foram obrigados a escolher entre o islã e a morte, cristãos árabes - aliados dos muçulmanos - foram coagidos a se converter (Friedmann 2006; Robinson 2000).

5 Sobre a formação da identidade islâmica no período abássida, ver Berkey (2003) e Lapidus (2002)

6 Segundo Cook (2005), essa tradição pode ser datada da segunda metade do século IX, quando estava começando a se definir a tradição mística no islã, o sufismo. Neste sentido, Crone (2005) afirma que é a partir do século X que começa a ocorrer uma resposta à acusação de outras religiões (judeus, cristãos, zoroastrianos) que o islã era uma religião que só se propaga devido à violência, e não devido à força de sua mensagem

7 Essas tradições de pensamento são paralelas, embora haja muitas vezes imbricações entre elas (juristas como al-Ghazali também foram grandes místicos). Assim, não é de espantar que as coleções "canônicas" de ahadith não contenham referências diretas à jihad espiritual (mas sim aos aspectos espirituais do jihad).

8 Disse Abu Musa: "Um homem veio até o Profeta e perguntou: 'Um homem luta por espólios; outro, por fama, e um terceiro, para se exibir; qual deles luta pela causa de Deus?' O Profeta respondeu: 'Aquele que luta para que a palavra de Deus seja superior, luta na causa de Deus'". Sahih Bukhari, Volume 4, Livro 52, nº 65.

9 Os ulemás (pl., do árabe ulamá; sing. aportuguesado álime, do árabe: álim) é um sábio do direito muçulmano que completou vários anos de estudo, e atua como mutfi (que interpreta a lei islâmica e emite fatwas); um cádi (juiz), um faqih (jurista) ou muhaddith (especialista nos hadith).

10 Não pretendo aqui explicar porque parte do ativismo islâmico recorre ao terrorismo, ou, inversamente, porque a maior parte não recorre.

11 "Auto-ajuda", neste sentido, quer dizer que os atores sociais em questão não recorrem a terceiros para realização de seus objetivos.

12 O levantamento se baseou em 28 grupos designados pelo Departamento de Estado como organizações terroristas internacionais. Esses grupos têm realizado operações terroristas, em média, desde 1978 (Abrahms 2006: 47-51).

13 Baseado em Lawrence e Howarth 2005; Ibrahim 2007 e Abrahms 2006.

14 Há outras acepções do termo, notadamente a designação de salafi ao movimento de renovação do pensamento islâmico iniciado no século XIX e baseado no Egito, cujas figuras de proa eram Muhammad Abduh (1849-1905), Jamal-al-Din Afghani (1839-1897) 
e Rashid Rida (1865-1935)

15 Os al-Saúd passaram por um período de declínio durante grande parte do século XIX, tendo sido derrotados pelos otomanos, mas finalmente conquistaram a Península Arábica no começo do século XX, estabelecendo o Reino da Arábia Saudita.

16 Sobre a noção de jihad segundo a doutrina wahhabita, ver Commins (2006) e Delong-Bas (2007).

17 O termo salafi-jihadi é recente, e parece ter sido cunhado nos anos 1980 ou 1990, tornando-se mais frequente após a invasão do Iraque em 2003 (Hegghammer 2010a.) A doutrina salafista-jihadista foi articulada pelo pensador islamista jordaniano Abu Muhammad al-Maqdisi (Wagemakers 2008a; 2009) e também difundida seu discípulo baseado em Londres, Abu Qatada al-Falastini.

18 Por "islamismo político" entende-se qualquer ideologia que pregue que a religião do Islã é também (ou deve ser manifestar na forma de) um sistema político próprio.

19 Sobre o surgimento e expansão dos Irmãos Muçulmanos, ver Mitchell (1993) e Lia (2006).

20 O emprego do binômio direito/ética aqui é proposital - a shari'a é tanto um direito quanto uma ética, e seus preceitos são tanto jurídicos, quanto religiosos e morais.

21 Para uma análise mais profunda sobre o jihad na Arábia Saudita, ver Hegghammer (2010). Para uma interpretação abrangente da ideologia de Uyayri, ver Meijer (2007). 
ABD AL-AZIZ, Abd al-Qadir ibn. 1988. al-usul al-khamsa li tahaqquq sunnat al-nasr aw takhallufiha (As cinco bases para conseguir a tradição da vitória ou sua ausência). In: al-'Umda fi l'dad al-'Udda lil Jihad fi Sabilillah al-Ta'ala (Os pilares para a preparação para o jihad no caminho de Deus o Altíssimo). Peshawar: Manuscrito.

ABRAHMS, Max. 2006. Why Terrorism Does Not Work. International Security, v. 31, n. 2: 42-78, Disponível em: <http:// www.mitpressjournals.org/doi/abs/10.1162/isec.2006.31.2.42>.

2008. What terrorists really want: Terrorist motives and counterterrorism strategy. Internationa/ Security, v. 32, n. 4: 78-105. Disponível em: <http://www.mitpressjournals.org/doi/abs/10.1162/isec.2008.32.4.78>.

AL-RASHEED, Madawi. 2006. Contesting the Saudi State: Is/amic Voices from a New Generation. Cambridge: Cambridge University Press.

AL-UYAYRI, Yusuf. 2009. Ma'ani al-nasr wa al-hazima fi al-jihad. Disponível em: <http://www.tawhed.ws/r?i=1502094e>. . s/d. Thawabit 'ala Darb al-Jihad (Constantes no Caminho do Jihad). Disponível em: <http://www.tawhed.

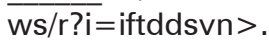

BERKEY, Jonathan. 2003. The Formation of /slam: Religion and Society in the Near East, 600-1800. Cambridge: Cambridge University Press.

BLACK, Donald. 2004. "Terrorism as Social Control". In Mathieu Deflem. (ed.). Terrorism and Counter-Terrorism. Amsterdam: Elsevier: 9-18.

BONNER, Michael. 2008. Jihad in Islamic History: Doctrines and Practice. Princeton: Princeton University Press.

COMMINS, David Dean. 2006. The Wahhabi mission and Saudi Arabia. Londres: I.B.Tauris.

COOK, David. 2005. Understanding Jihad. Berkeley: University of California Press.

CRONE, Patricia. 2005. God's Rule - Government and Islam: Six Centuries of Medieval Is/amic Political Thought. New York: Columbia University Press.

DABASHI, Hamid. 2008. Iran: A People Interrupted. New York: New Press.

DELONG-BAS, Natana J. 2007. Wahhabi Islam: from revival and reform to global jihad. Londres: I.B.Tauris.

DEVJI, Faisal. 2005. Landscapes of the Jihad: Militancy, Morality, Modernity. Ithaca: Cornell University Press.

ESPOSITO, John. 2002. Unholy War: Terror in the Name of Islam. Oxford: Oxford University Press.

FRIEDMANN, Yohanan. 2003. Tolerance and Coercion in Islam: Interfaith Relations in the Muslim Tradition. Cambridge: Cambridge University Press.

HEGGHAMMER, Thomas. 2010a. "Jihadi-salafis or revolutionaries? On religion and politics in the study of radical Islam." In MEIJER, Roel. 2009. Global Salafism: Islam's New Religious Movement. Londres: C Hurst \& Co Publishers.

2010b. Jihad in Saudi Arabia: Violence and Pan-Islamism Since 1979. Cambridge: Cambridge University Press.

IBRAHIM, Raymond. 2007. The A/ Qaeda Reader. New York: Broadway Books.

KANT, Immanuel. 1993 (1785) Grounding for the metaphysics of morals; with, On a supposed right to lie because of 
philanthropic concerns. [S.I.]: Hackett Publishing Company.

KEPEL, Gilles. 2003a. Jihad. Paris: Editions Gallimard.

2003b. Muslim Extremism in Egypt: The Prophet and the Pharaoh. Berkeley and Los Angeles: University of California Press.

LAPIDUS, Ira M. 2002. A History of Islamic Societies. Cambridge: Cambridge University Press.

LAWRENCE, B.; Howarth, J. 2005. Messages to the world: the statements of Osama bin Laden. London: Verso Books.

LIA, Brynjar. 2006. The Society of the Muslim Brothers in Egypt: The Rise Of an Islamic Mass Movement 1928-1942. $1^{\text {a }}$ ed. Ithaca Press (GB).

MEIJER, Roel. 2007. Yusuf al-Uyayri and the making of a revolutionary Salafi praxis. Die Welt des Is/ams 47 (3-4): 422-59. 2009. Global Salafism: Islam's New Religious Movement. Londres: C Hurst \& Co Publishers Ltd.

MITCHELL, Richard P. 1993. The Society of the Muslim Brothers. Oxford University Press.

PETERS, Rudolph \& Gert J. J. Devries. 1976-1977. Apostasy in Islam. Die Welt des Islams, 17(1-4): 1-25.

ROBINSON, Chase F. 2000. Empire and Elites after the Muslim Conquest: The Transformation of Northern Mesopotamia. Cambridge: Cambridge University Press.

ROY, Olivier. 2004. L'slam mondialisé. Paris: Seuil.

TYAN, E. 1991. "Djihad". In Lewis, B. et al. (Ed.). Encyclopedia of Islam. Leiden: Brill, vol. II: 538-540.

WAGEMAKERS, Joas. 2008a. Defining the enemy - Abu Muhammad al-Maqdisi's radical reading of Surat al-Mumtahana. Die Welt des Islams, vol. 48 (3-4), pp. 348-371. (4): 1-22.

2008b. "Framing the "threat to islam": al-wala' wa al-bara' in Salafi discourse". Arab Studies Quarterly, vol. 30

2009. A Purist Jihadi-Salafi: The Ideology of Abu Muhammad al-Maqdisi. British Journal of Middle Eastern Studies. 36(2): 281-297.

WATT, Montgomery. 1970. "Muhammad". In P. M. Holt; Ann Lambton \& Bernard Lewis (eds.). The Cambridge History of Islam. Vol. 1A. The Central Islamic Lands from Pre-Islamic Times to the First World War. Cambridge: Cambridge University Press.

WIKTOROWICZ, Quintan. 2001. The Management of Islamic Activism: Salafis, the Muslim Brotherhood, and State Power in Jordan. New York: State University of New York Press.

2003. Islamic Activism: A Social Movement Theory Approach. Bloomington: Indiana University Press.

WRIGHT, Lawrence. "The rebellion within". New Yorker, 6/2/2008, Vol. 84, Issue 16: 36-53. 


\section{Jihad: Duas interpretações contemporâneas de um conceito polissêmico}

\section{RESUMO}

Quais são os papéis e os significados do conceito de jihad para os movimentos islamistas contemporâneos? O objetivo deste artigo é apresentar duas releituras contemporâneas do conceito de jihad - entendido este como luta armada e militância pública - através da análise das obras de dois pensadores islamistas contemporâneos, Sayid Imam e Yusuf al-Uyayri, em cujos escritos se torna evidente a concepção do jihad como luta moral e ascese. A especificidade das leituras do jihad em contextos contemporâneos é que ele se individualiza, tornando-se, ele próprio, um "modo de vida" e uma escolha no plano individual, sendo reformulado e vivido por pensadores e militantes islâmicos alheios tanto às instituições tradicionais de transmissão do conhecimento religioso islâmico quanto ao Estado. Os percursos diversos de vida e as obras de Sayid Imam e Yusuf al-Uyayri podem ser, assim, lidas como exemplo de um enfoque distinto do tema de jihad entre os militantes islâmicos.

PALAVRAS-CHAVE: jihad; islamismo; terrorismo.

\section{Jihad: Two contemporary interpretations of a polysemous concept}

\section{ABSTRACT}

What are the roles and meanings of the concept of jihad for contemporary Islamic movements? The objective of this article is to present two contemporary readings of the concept of jihad - taken here to mean armed struggle and public activism - through the analysis of the works of two contemporary Islamist thinkers, Sayid Imam and Yusuf al-Uyayri, in whose writings the conception of jihad as moral struggle and asceticism becomes evident. The specific feature of contemporary readings of jihad is that it is now individualized, becoming a "way of life" in itself, an individual choice. This new meaning of jihad is reformulated and lived by Islamic thinkers and militants apart both from traditional institutions of religious learning and from the State. The lives and works of Sayid Imam and Yusuf al-Uyayri can thus be regarded as instances of a distinct view on jihad among Islamic militants.

KEYWORDS: jihad; Islamism; terrorism. 